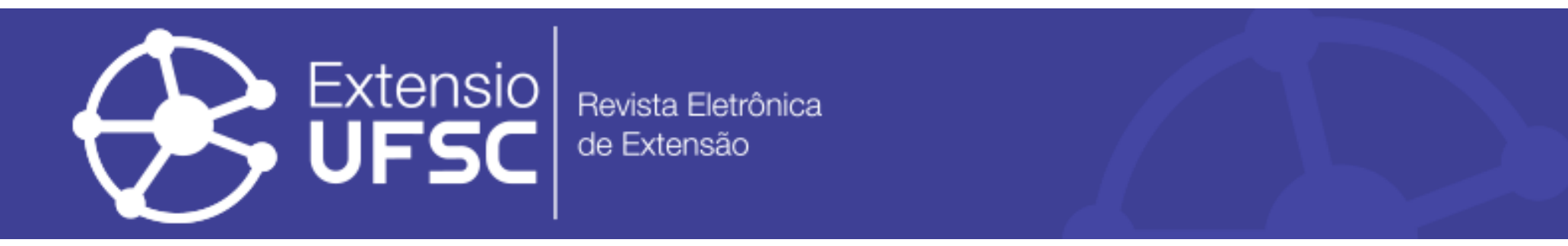

\title{
DESENVOLVIMENTO DE UMA UNIDADE DEMONSTRATIVA DE PRODUÇÃO AGROECOLÓGICA DE LEITE EM ASSENTAMENTO RURAL
}

\author{
Ana Maria Bridi \\ Universidade Estadual de Londrina \\ ambridi@uel.br
}

Carolina Amália de Souza Dantas Muniz Universidade Estadual de Londrina muniz@uel.br

Amanda Massaneira de Souza Schuntzemberge Universidade Estadual de Londrina amandamss@uel.br

Laís Sodre Santana

Universidade Estadual de Londrina laissosant@gmail.com
Évelyn Rangel dos Santos Universidade Estadual de Londrina evelyn-rangel@hotmail.com

Tainá Scabori Vargas Universidade Estadual de Londrina scabori.taina@gmail.com

Thamires Aparecida Marinho Universidade Estadual de Londrina marinhothamires1997@gmail.com

Valter Harry Bumbieris Junior Universidade Estadual de Londrina jrbumbieris@uel.br

Sandra Galbeiro

Universidade Estadual de Londrina sgalbeiro@uel.br

\section{Resumo}

Objetivou-se relatar as atividades desenvolvidas pelo projeto de extensão no Assentamento Rural Eli Vive, demonstrando a integração entre discentes, docentes e assentados. O projeto foi coordenado pelo Grupo PET (Programa de Educação Tutorial) do Curso de Zootecnia da Universidade Estadual de Londrina, sendo realizado no assentamento Eli Vive, município de Londrina (PR), utilizando a metodologia "Planejamento Estratégico Participativo", durante os anos de 2014a 2018. Foram realizadas visitas técnicas e atividades sobre temas que envolvem a cadeia produtiva de leite. Foi implementada uma Unidade Demonstrativa de Produção de Leite em Pastagem. Também foram desenvolvidas atividades visando à produção de alimentos para o rebanho e confeccionado um manual técnico "Produção Agroecológica de Leite". Com o presente projeto, foi possível detectar e solucionar problemas, buscar inovações de baixo custo para o sistema de produção, implementar aspectos agroecológicos de produção e capacitar os assentados,beneficiando a produtividade e a qualidade do produto final e melhorando a qualidade de vida dos assentados.

Palavras-chave: Agricultura Familiar. Extensão. Produção Agroecológica.

\section{PARTICIPATORY DEVELOPMENT OF THE SUSTAINABLE MILK PRODUCTIVE CHAIN IN RURAL SETTTING}

\begin{abstract}
The objective was to report on the activities developed by the extension project in the Eli Vive Rural settlement, demonstrating the integration among students, teachers and settlers. The project was coordinated by the PET Group (Education Program Tutorial) of the Zootechny Course of the State University of Londrina, being carried out in the Eli Vive settlement, located in the city of Londrina (PR), the project was developed using the methodology "Participative Strategic Planning", from 2014 to 2018. Technical visits and activities were carried out on topics involving the milk production chain. A Demonstrative Unit for Pasture Milk Production was implemented. Activities were also developed to produce food for the herd and a technical manual "Agroecological Milk Production" was produced. With the present project, it was possible to detect and solve problems, seek low cost innovations for the production system, implement agroecological aspects of production and train settlers, benefiting the productivity and quality of the final product and improving the quality of life of the settlers.
\end{abstract}

Keywords: Family Farming. Extension. Agroecological Production. 


\section{DESARROLLO PARTICIPATIVO DE LA CADENA PRODUCTIVA SOSTENIDA DE LECHE EN ASENTAMIENTO RURAL}

\section{Resumen}

El objetivo fue informar lãs actividades desarrolladas por el proyecto de extensión em el asentamiento rural Eli Vive, demostrando la integración entre estudiantes, maestros y colonos. El proyecto está coordinado por el Grupo PET (Programa de Educación Tutorial) del Departamento de Zootecnia de la Universidad Estatal de Londrina, que se lleva a cabo en el asentamiento Eli Vive, ubicado en la ciudad de Londrina (PR), utilizando la metodología "Planificación Estratégica Participativa ", de 2014 a 2018. Se realizaron visitas técnicas y actividades sobre temas relacionados con la cadena de producción de leche. Se implementó una Unidad de Producción de Leche Demostrativa en Pasto. También se desarrollaron actividades destinadas a la producción de alimentos para el rebaño y se preparo un manual técnico "Producción de leche agroecológica". Con este proyecto, fue posible detectar y resolver problemas, buscar innovaciones de bajo costo para el sistema de producción, implementar aspectos agroecológicos de producción y capacitar a los colonos, beneficiando la productividad y lacalidad del producto final y mejorando la calidad de vida de los colonos.

Palavras clave: Agricultura Familiar. Extensión. Producción Agroecológica. 
Desenvolvimento de uma unidade demonstrativa de produção agroecológica de leite em assentamento rural

\section{INTRODUÇÃO}

A extensão rural universitária contribui notavelmente para o desenvolvimento dos agricultores familiares, visto que o uso de metodologias participativas, princípios agroecológicos na assistência técnica e atividades propostas melhoram não somente a produção, mas a qualidade de vida dos assentados. Os discentes envolvidos no projeto de extensão conquistam a oportunidade de aplicar na prática os conhecimentos e tecnologias adquiridos na Universidade, além de despertar o interesse sobre os assuntos abordados e adquirir novas experiências (VASQUEZ, FONSECA, 2014).

O contato da Universidade com os assentados permite a reflexão sobre a adoção de tecnologia. Alguns sistemas e metodologias de produção podem parecer simples, porém só alcançam determinados resultados com a assistência do extensionista rural, que, diante da demanda por soluções que visem à viabilidade dos sistemas produtivos em assentamentos e sejam aplicáveis à realidade encontrada, tem a possibilidade de atender às necessidades de melhoria da produção e aumento de renda.

Dessa forma, o trabalho em conjunto da Universidade e dos assentamentos, por meio de seus atores -estudantes, professores e assentados- traduz a utilização de tecnologias em linguagem acessível, transportando o conhecimento técnico desenvolvido na Universidade à sua aplicabilidade nos assentamentos rurais. Diante desse cenário, é possível,por meio da adoção de tecnologias que visem à maximização da produção de leite, melhorar a qualidade de vida dos assentados.

Deve-se salientar que a decisão na adoção de tecnologia deve ser discutida com a comunidade, assim a utilização de uma metodologia que permita a participação dos assentados nas decisões é de extrema importância para sua implantação. Dessa forma, utilizou-se a metodologia do "Planejamento Estratégico Participativo" (PEP). Segundo Kummer (2007), a metodologia consiste na estruturação e organização das ações a partir da reflexão e decisão da maioria, em benefício da maioria. Rocha et al. (2001) salientam que o PEP, além de definir as necessidades e aspirações do grupo, serve também para nortear futuros trabalhos de organização.

No assentamento Eli Vive em Londrina - PR, aproximadamente 4,5\% das famílias se dedicam à pecuária leiteira. Apesar de ser um percentual pequeno, exprime certa vocação para a atividade. O leite produzido pelos assentados é captado pela Cooperativa de Comercialização e Reforma Agrária União Camponesa, localizada no Assentamento Rural Dorcelina Folador, no município de Arapongas - PR, o que coloca também os produtores do Eli Vive em contato com 
Desenvolvimento de uma unidade demonstrativa de produção agroecológica de leite em assentamento rural

o sistema de Cooperativa, com outros produtores e assim a possibilidade da criação de um ambiente de interesse na cadeia produtiva do leite.

Para que a produção leiteira seja significativa, são necessárias medidas de utilização de tecnologia, assim a interação entre os assentados e a Universidade torna-se muito interessante. A produção de leite pode ser incrementada, por meio da seleção de vacas produtivas, descarte de vacas improdutivas, aquisição de animais geneticamente superiores, do manejo e preservação da pastagem de forma adequada, da produção de culturas de inverno, da implementação do pastejo rotacionado, de um sistema de irrigação, de boas práticas de ordenha, de princípios de administração rural e cuidados com os recém-nascidos (GONÇALVES et al., 2014).

Ainda a adoção de técnicas que considerem as especificidades ecológicas e minimizem o impacto ambiental podem incrementar de maneira expressiva a produção de leite nessas áreas.A aplicação de conceitos que favoreçam a produção sustentável e reduzam a agressão ao meio ambiente contribui para que os produtos sejam de excelente qualidade e tenham o diferencial agroecológico agregado (COSTABEBER, CAPORAL, 2003).

O objetivo do presente trabalho foi relataras atividades desenvolvidas pelo projeto de extensão "Desenvolvimento participativo da cadeia produtiva sustentável de leite no assentamento rural Eli Vive",salientando a integração entre a instituição de ensino (discentes e docentes) e a comunidade externa (assentados), visando à produção sustentável de leite.

\section{MATERIAL E MÉTODOS}

O Projeto de Extensão "Desenvolvimento Participativo da Cadeia Produtiva Sustentável de Leite em Assentamento Rural" foi desenvolvido no Assentamento Rural Eli Vive I e Eli Vive II, durante os anosde2014 e 2018. O Projeto foi coordenado pelo Grupo PET (Programa de Educação Tutorial) do Curso de Zootecnia em parceria com a Empresa Júnior de Zootecnia (CATECz),docentes e discentes do Centro de Ciências Agrárias (Agronomia, Medicina Veterinária e Zootecnia) da Universidade Estadual de Londrina - UEL. Colaboraram ainda com o projeto, docentes pesquisadores vinculados aos Programas de Pós-Graduação (Ciência Animal e Agronomia).

O projeto de extensão foi conduzido com base na metodologia participativa denominada "Planejamento Estratégico Participativo" (PEP), onde o planejamento das atividades a serem desenvolvidas na comunidade foram elencadas e priorizadas pelos próprios membros da comunidade. 
Desenvolvimento de uma unidade demonstrativa de produção agroecológica de leite em assentamento rural

O assentamento Eli Vive, criado no ano de 2010, é dividido em duas unidades (Eli Vive I e II), localiza-se no município de Londrina (PR), em uma área de 7.313,06 hectares. É considerado um dos maiores assentamentos rurais do Brasil com 540 famílias assentadas, sendo que cada família possui um lote terra de 9,0 ha a 13,0 ha.

No início do projeto, 24 famílias assentadas possuíam bovinos de leite em suas propriedades. Assim, formou-se um grupo de assentados com interesse em bovinocultura leiteira. A partir desse grupo, foram realizadas reuniões com o grupo do projeto (assentados, discentes e docentes) para discutir interesses comuns, agendar tarefas e estabelecer formas conjuntas de atuação. Após o início das atividades, além de discutir as ações previstas, eram analisadas as ações já realizadas no âmbito do projeto e os resultados obtidos, visando adequar às novas estratégias.

Com os recursos obtidos por meio da aprovação do projeto no edital da Secretaria de Estado da Ciência, Tecnologia e Ensino Superior - SETI PR (Programa de Extensão Universitária Universidade Sem Fronteiras) foram desenvolvidas atividades com o objetivo de auxiliar os produtores do assentamento no desenvolvimento da produção agroecológica de leite. Os recursos permitiram ainda a concessão de bolsas para duas profissionais recém-formadas em Zootecnia e Medicina Veterinária e para uma estudante de graduação em Zootecnia.

Foi determinada uma propriedade no assentamento Eli Vive I para a formação de uma Unidade Demonstrativa de Produção de Leite em Pastagem (UDPLP). Os acadêmicos cadastrados no projeto, sob a supervisão dos docentes, elaboraram um projeto técnico de produção de leite em pastagem, o qual foi implantado entre os anos de 2016/2017. Após a realização do levantamento topográfico da área, foram construídas as cercas elétricas para a divisão dos piquetes, os bebedouros e a implantação das pastagens. A UDPLP foi utilizada como modelo de um sistema de produção de leite em pastagem, servido assim de referência para os demais assentados.

Foram realizadas mensalmente, na UDPLP e no Centro Comunitário, atividades dinâmicas (dia de campo, palestras e oficinas) sobre temas que envolvem a cadeia produtiva de leite, como produção, conservação e manejo de forragens; manejo nutricional e cálculo de ração de acordo com os ingredientes disponíveis; projetos de instalações (divisão de áreas, construção e manutenção de cercas elétricas, sala de ordenha); manejo sanitário do rebanho; manejo produtivo e manejo da ordenha e administração da produção. As atividades foram organizadas pelos acadêmicos e ministradas pelos professores do Centro de Ciências Agrárias da UEL.

Além disso, quinzenalmente os assentados recebiam visitas técnicas em suas propriedades, dos docentes e discentes do projeto, nas quais foram relatados e/ou identificados problemas e dúvidas relacionadas à produção. Quando possível, o problema era solucionado 
Desenvolvimento de uma unidade demonstrativa de produção agroecológica de leite em assentamento rural

imediatamente e quando não, os alunos, juntamente com docentes e pós-graduandos, buscavam por meio da Universidade alternativas para solucionar ou minimizar os problemas em questão.

$\mathrm{Na}$ Universidade foram realizadas reuniões semanais com docentes e discentes envolvidos no projeto, nas quais além de discutir as resoluções dos problemas encontrados no assentamento, eram discutidos os planos de ação, ajuste de calendário de atividades, leitura e interpretação de manuais, resumos e artigos com metodologias que permitiram maior entendimento da ação extensionista e contribuíram para o desenvolvimento do projeto.

Todas as atividades realizadas foram registradas em ata, em fichas de participação e fotos, para posteriores consultas. O projeto contou ainda com uma página em rede social, como objetivo de divulgar as atividades realizadas para a comunidade externa e acadêmica.

\section{RESULTADOS E ANÁLISES}

As várias atividades realizadas juntamente com os assentados são descritas no Quadro 1.

$\mathrm{Na}$ UDPLP do assentamento, foi implantado o pastejo rotativo para bovinos de leite (Figura 1). Para tanto, foi realizado inicialmente um levantamento topográfico com a finalidade de subdividir a área total do pasto em piquetes e fazer as demarcações para a colocação das cercas elétricas e bebedouros.

A atividade foi realizada visando proporcionar períodos regulares de descanso do pasto, favorecendo a rebrota das forrageiras e o melhor aproveitamento da forragem produzida, devido a maior uniformidade de pastejo e, consequentemente, à melhoria da produtividade das vacas leiteiras (ANDRADE, 2008).Já as soluções dos problemas encontrados para as cercas possibilitaram a economia de energia e o uso adequado dos materiais para a separação dos piquetes.

Foram desenvolvidas também atividades visando à produção de alimentos conservados para o rebanho para a época seca do ano, como a silagem e o feno, além do plantio de forrageira de inverno. A prática da sobressemeadura de aveia foi realizada com sucesso na UDPLP, instruindo os produtores e expondo os fatores necessários para efetivação da técnica e desenvolvimento da cultura, dando-lhes assim a possibilidade de garantir mais uma opção de alimentação dos animais no inverno. De acordo com as demandas, foram realizados projetos de silose projeção de área de forrageiras a ser semeada para a confecção de silagem (levando em conta o tamanho do rebanho, tempo de suplementação e quantidade fornecida por animal).

No inverno, devido à baixa disponibilidade de forragem, ocorre a diminuição da produção leiteira e, consequentemente, o preço do leite pago ao produtor nesse período é maior. 
Desenvolvimento de uma unidade demonstrativa de produção agroecológica de leite em assentamento rural

Nesse sentido, a aplicação das técnicas de conservação e produção de forragens de inverno favorece o produtor, pela manutenção da produção de leite mais estável ao longo do ano, diminuindo o efeito da entressafra em sua renda.

Figura 1. Unidade Demonstrativa de Produção de Leite em Pastagem. (a) Divisão dos piquetes; (b) Curso prático sobre implantação e manutenção de cerca elétrica; (c) Curso sobre sobressemeadura de aveia.

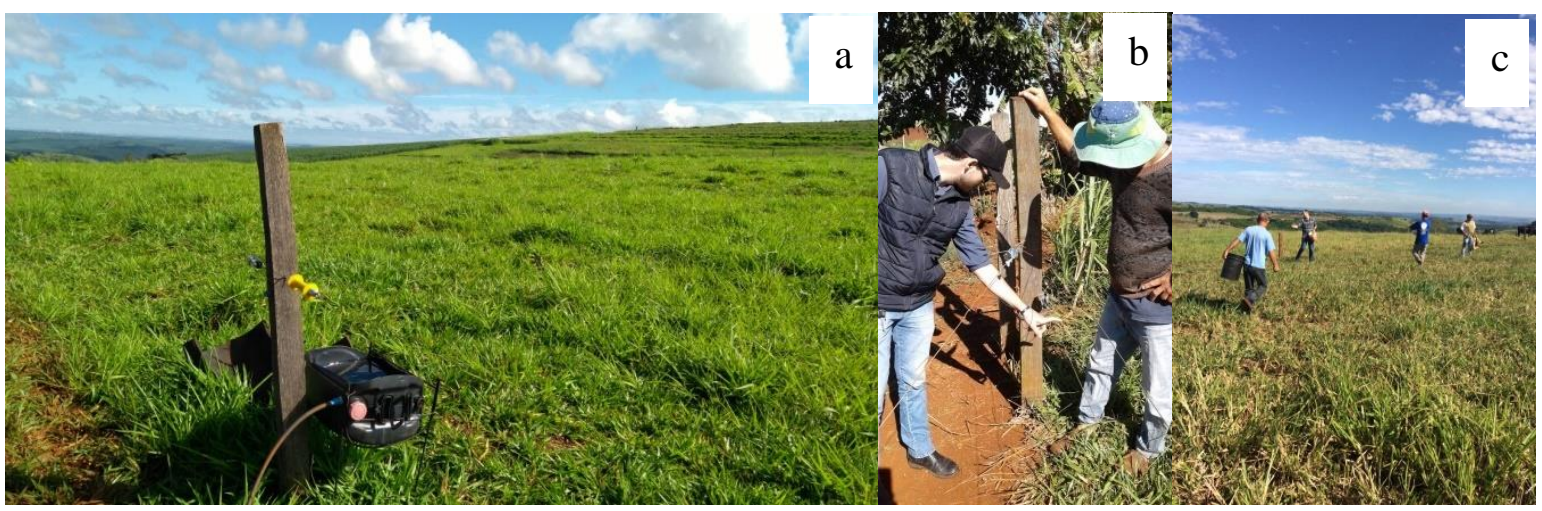

Fonte: Acervo do projeto

Visando melhorar a qualidade microbiológica do leite e, consequentemente, melhorar a remuneração dos produtores que recebem gratificações pela qualidade do leite entregue à Cooperativa, foi realizado um treinamento para os produtores sobre boas práticas de higiene na ordenha, mostrando que é possível reduzir a contagem bacteriana do leite (CBT), os cuidados com resíduos de antibióticos e saúde dos animais (BATTAGLINI et., 2013). O treinamento foi dividido em três etapas: palestra sobre ordenha higiênica; acompanhamento das ordenhas nas propriedades, e visita ao Laboratório da Inspeção de Produtos de Origem Animal da UEL (LIPOA), onde os assentados puderam acompanhar como são realizadas as análises do leite e conferir os resultados dos testes realizados com as amostras de leite coletadas no assentamento.

Como o pilar da produção de leite é a sanidade, foi elaborado um calendário sanitário, indicando quais as vacinas, dose, idade a ser administrada e os cuidados na administração. Após a elaboração do calendário, foi realizada uma reunião para apresentar o mesmo, bem como para explicar a importância da sanidade do rebanho para garantir a produção e a qualidade do leite. Ainda na linha de sanidade, os assentados tiveram um curso sobre manejo racional do gado leiteiro nos procedimentos clínicos, ministrado por um professor do Curso de Medicina Veterinária da UEL (Figura 2). 
Desenvolvimento de uma unidade demonstrativa de produção agroecológica de leite em assentamento rural

Figura 2 - Sanidade do rebanho leiteiro. (a) Manejo sanitário do rebanho; (b) Manejo sanitário da ordenha.

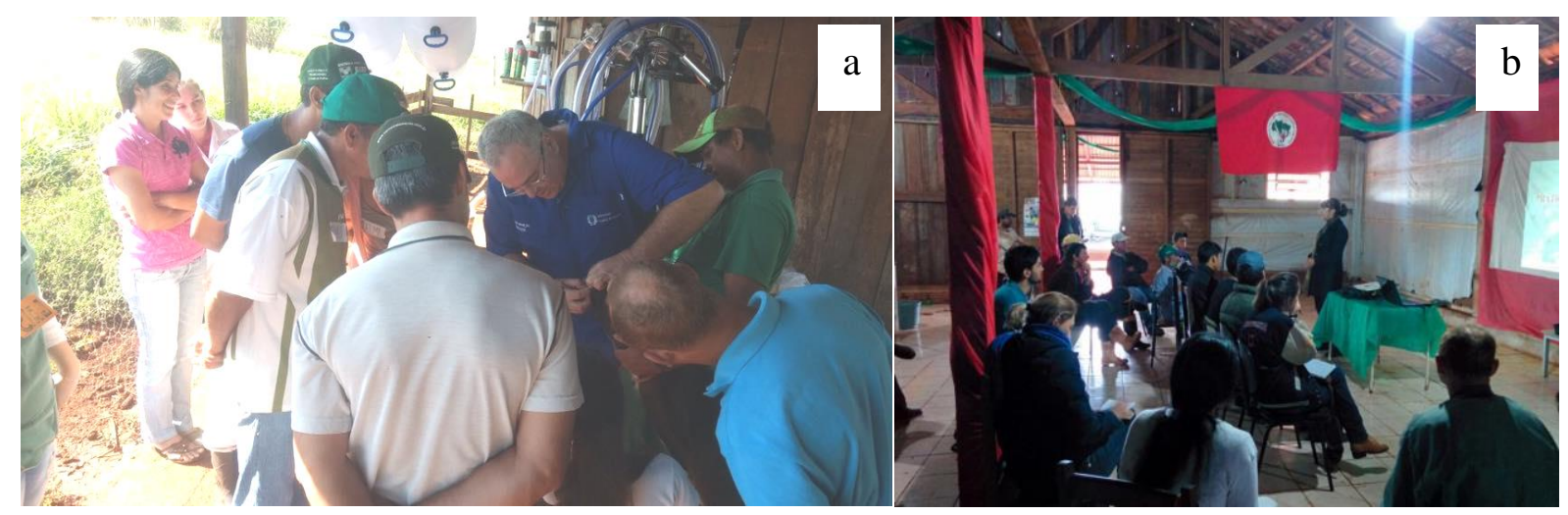

Fonte: Acervo do projeto

Visando proporcionar material para consulta, foi desenvolvido um manual técnico intitulado "Produção Agroecológica de Leite", abordando aspectos de instalações, nutrição, manejo e sanidade do gado leiteiro, além de um banner explicativo com parâmetros relacionados à composição e qualidade do leite (requisitos microbiológicos e contagem de células somáticas), com a finalidade de proporcionar conhecimento acessível e permanente aos assentados com respeito à produção das vacas leiteiras.

O curso de derivados lácteos possibilitou o conhecimento e aprimoramento da preparação de produtos como queijo frescal, iogurte, coalhada seca, requeijão e doce de leite.Foi possível ainda o aperfeiçoamento das boas práticas de produção, pelo enfoque na importância da higiene pessoal no preparo dos alimentos e da pasteurização do leite in natura antes do preparo dos derivados lácteos. Esse fato possibilita a diversificação da fonte de renda para os homens e, principalmente, para as mulheres, visando ao empoderamento feminino e à afirmação da autoestima da mulher, por meio de sua independência financeira.

Quadro 1 - Atividades desenvolvidas pelo projeto de extensão no Assentamento rural Eli Vive, no ano letivo de 2017.

\begin{tabular}{|l|l|l|}
\hline Nome da atividade & Descrição da atividade & Participantes \\
\hline Divisão de piquetes & $\begin{array}{l}\text { Levantamento topográfico da } \\
\text { área, elaboração do projeto de de } \\
\text { divisão dos piquetes, construção } \\
\text { da cerca elétrica. }\end{array}$ & $\begin{array}{l}\text { Proprietário da unidade demonstrativa, } \\
\text { bolsistas recém-formadas, bolsista de } \\
\text { graduação e alunos de graduação em } \\
\text { Zootecnia. }\end{array}$ \\
\hline $\begin{array}{l}\text { Curso sobre cercas } \\
\text { elétricas }\end{array}$ & $\begin{array}{l}\text { Explicação, solução de dúvidas e } \\
\text { demonstrações sobre a a a a } \\
\text { montagem e manutenção de de } \\
\text { cercas elétricas na UDPLP. }\end{array}$ & $\begin{array}{l}\text { Especialista em cercas, proprietário da } \\
\text { unidade demonstrativa, bolsistas recém- } \\
\text { formadas, bolsista de graduação e aluna de } \\
\text { graduação em Zootecnia. }\end{array}$ \\
\hline $\begin{array}{l}\text { Manejo racional do } \\
\text { gado leiteiro nos }\end{array}$ & Curso prático na UDPLP. & $\begin{array}{l}\text { Docente do Departamento de Clínicas } \\
\text { Veterinárias da UEL (ministro do curso), }\end{array}$ \\
\hline
\end{tabular}


Desenvolvimento de uma unidade demonstrativa de produção agroecológica de leite em assentamento rural

\begin{tabular}{|c|c|c|}
\hline procedimentos clínicos & & $\begin{array}{l}\text { bolsista recém-formada, bolsista } \\
\text { graduação, alunos de graduação em } \\
\text { Zootecnia e assentados. }\end{array}$ \\
\hline $\begin{array}{l}\text { Alternativas de } \\
\text { alimentação de inverno } \\
\text { para o gado leiteiro }\end{array}$ & $\begin{array}{l}\text { Palestra e demonstração } \\
\text { desobressemeadura de aveia preta } \\
\text { em um dos piquetes da UDPLP. }\end{array}$ & $\begin{array}{l}\text { Docente do Departamento de Zootecnia } \\
\text { da UEL (palestrante), bolsistas recém- } \\
\text { formadas, estudante de graduação e } \\
\text { assentados }\end{array}$ \\
\hline $\begin{array}{l}\text { Produção de derivados } \\
\text { lácteos }\end{array}$ & $\begin{array}{l}\text { Curso prático, realizado na } \\
\text { Escola Tecnológica de Laticínios } \\
\text { da Universidade Estadual do } \\
\text { Norte do Paraná (UENP), } \\
\text { Campus de Bandeirantes - PR. }\end{array}$ & $\begin{array}{l}\text { Docente (ministro do curso) e técnica da } \\
\text { Escola Tecnológica de Laticínios (UENP), } \\
\text { bolsistas recém-formadas e assentados. }\end{array}$ \\
\hline $\begin{array}{l}\text { Nutrição e sanidade na } \\
\text { bovinocultura de leite }\end{array}$ & $\begin{array}{l}\text { Palestra realizada no Centro } \\
\text { Comunitário do Assentamento. } \\
\text { Elaboração de um calendário } \\
\text { sanitário para o rebanho. }\end{array}$ & $\begin{array}{l}\text { Docente do Departamento de Clínicas } \\
\text { Veterinárias da UEL (palestrante), docente } \\
\text { do Departamento de Zootecnia, bolsistas } \\
\text { recém-formadas, estudantes de graduação } \\
\text { em Zootecnia e assentados. }\end{array}$ \\
\hline Correção de solo & $\begin{array}{l}\text { Coleta e análise das amostras de } \\
\text { solo. Correção do solo e } \\
\text { adubação das pastagens na } \\
\text { UDPLP. }\end{array}$ & $\begin{array}{l}\text { O proprietário da unidade demonstrativa, } \\
\text { e bolsista recém-formado. Laboratório de } \\
\text { análise de solos da UEL. }\end{array}$ \\
\hline $\begin{array}{l}\text { Manutenção da } \\
\text { ordenhadeira mecânica }\end{array}$ & $\begin{array}{l}\text { Visita às linhas de ordenha. Curso } \\
\text { na UDPLP sobre a manutenção e } \\
\text { limpeza da ordenhadeira } \\
\text { mecânica. }\end{array}$ & $\begin{array}{l}\text { O proprietário da unidade demonstrativa, } \\
\text { bolsistas recém-formadas, estudante de } \\
\text { graduação em Zootecnia, Médico } \\
\text { Veterinário Residente em Inspeção de } \\
\text { Leite e Derivados do Hospital Veterinário } \\
\text { da UEL. }\end{array}$ \\
\hline $\begin{array}{l}\text { Escrituração } \\
\text { zootécnica }\end{array}$ & $\begin{array}{l}\text { Palestra realizada no centro } \\
\text { comunitário do Assentamento } \\
\text { Acompanhamento do } \\
\text { preenchimento das fichas pelos } \\
\text { assentados. }\end{array}$ & $\begin{array}{l}\text { Docente do Departamento de Zootecnia } \\
\text { da UEL (palestrante), bolsistas recém- } \\
\text { formadas, estudantes de graduação em } \\
\text { Zootecnia, estudante de graduação em } \\
\text { Medicina Veterinária e assentados. }\end{array}$ \\
\hline Compostagem & $\begin{array}{l}\text { Discussão sobre métodos } \mathrm{de} \\
\begin{array}{l}\text { compostagem realizado } \\
\text { unidade demonstrativa. }\end{array}\end{array}$ & $\begin{array}{l}\text { Docente do Departamento de Agronomia } \\
\text { da UEL, bolsistas recém-formadas, } \\
\text { estudantes de pós-graduação em Ciência } \\
\text { Animal. }\end{array}$ \\
\hline Carneiro hidráulico & $\begin{array}{l}\text { Instalação de um } \\
\text { hidráulico carneiro } \\
\text { demonstrativa. }\end{array}$ & $\begin{array}{l}\text { Docente do Departamento de Zootecnia } \\
\text { da UEL, bolsistas recém-formadas, } \\
\text { estudantes de graduação em Zootecnia } \\
\text { eestudante de pós-graduação em Ciência } \\
\text { Animal. }\end{array}$ \\
\hline $\begin{array}{l}\text { Proteção e conservação } \\
\text { de minas d'água }\end{array}$ & $\begin{array}{l}\text { Palestra realizada no Centro } \\
\text { Comunitário do Assentamento. }\end{array}$ & $\begin{array}{l}\text { Técnica da } \\
\text { (palestrante),Departamento de Zootecnia } \\
\text { da UEL, estudantes de graduação em } \\
\text { Zootecnia e assentados. }\end{array}$ \\
\hline $\begin{array}{l}\text { Fitoterápicos/ } \\
\text { Homeopáticos }\end{array}$ & $\begin{array}{l}\text { Palestra realizada no Centro } \\
\text { Comunitário do Assentamento. }\end{array}$ & $\begin{array}{l}\text { Aluna de Pós-Graduação (palestrante), } \\
\text { Docente do Departamento de Zootecnia, } \\
\text { bolsistas recém-formadas, estudantes de } \\
\text { Zootecnia e assentados. }\end{array}$ \\
\hline $\begin{array}{l}\text { Implantação } \\
\text { pastagens }\end{array}$ & $\begin{array}{l}\text { Palestra realizada no Centro } \\
\text { Comunitário do assentamento. }\end{array}$ & $\begin{array}{l}\text { Docente do Departamento de Zootecnia } \\
\text { da UEL, bolsistas recém-formadas, alunos } \\
\text { de graduação, assentados. }\end{array}$ \\
\hline $\begin{array}{l}\text { Conservação } \\
\text { forragens }\end{array}$ & $\begin{array}{l}\text { Palestra realizada no Centro } \\
\text { Comunitário do assentamento. }\end{array}$ & $\begin{array}{l}\text { Docente do Departamento de Zootecnia } \\
\text { da UEL, bolsistas recém-formadas, alunos } \\
\text { de graduação, assentados. }\end{array}$ \\
\hline
\end{tabular}


Desenvolvimento de uma unidade demonstrativa de produção agroecológica de leite em assentamento rural

\begin{tabular}{|l|l|l|}
\hline $\begin{array}{l}\text { Produção orgânica de } \\
\text { leite }\end{array}$ & $\begin{array}{l}\text { Palestra realizada no Centro } \\
\text { Comunitário do assentamento. }\end{array}$ & $\begin{array}{l}\text { Docente do Departamento de Zootecnia } \\
\text { da UEL, bolsistas recém-formadas, alunos } \\
\text { de graduação, assentados. }\end{array}$ \\
\hline Higiene da ordenha & $\begin{array}{l}\text { Palestra realizada no Centro } \\
\text { Comunitário do assentamento e e } \\
\text { na Unidade Demonstrativa. }\end{array}$ & $\begin{array}{l}\text { Docente do Departamento de Zootecnia } \\
\text { da UEL, bolsistas recém-formadas, alunos } \\
\text { de graduação, assentados. }\end{array}$ \\
\hline Higiene da ordenha & $\begin{array}{l}\text { Prática em algumas ordenhas dos } \\
\text { produtores no assentamento. }\end{array}$ & $\begin{array}{l}\text { Docente do Departamento de Zootecnia } \\
\text { da UEL, bolsistas recém-formadas, alunos } \\
\text { de graduação, assentados. }\end{array}$ \\
\hline
\end{tabular}

A escrituração zootécnica do rebanho visou ao controle da produção leiteira, por meio da coleta de dados, como data de nascimento, identificação do animal, ocorrências no parto, cobrição, dados do bezerro nascido e o controle da produção de leite. Dessa forma, torna-se possível acompanhar a evolução do rebanho com o objetivo da previsão da produção de alimento, a produção de leite, a produtividade e, consequentemente, rentabilidade do sistema.

A atividade sobre compostagem teve o propósito de abordar métodos de destino de resíduos orgânicos no sistema de produção e ressaltara importância da compostagem para o meio ambiente, visto que é uma ótima opção para reciclar matéria orgânica, além disso, o produto gerado após esse processo de degradação é o composto orgânico, que pode ser utilizado como adubo, devolvendo à terra os nutrientes necessários, evitando assim a utilização de fertilizantes para uso agrícola.

O assentamento possui áreas com declives acentuados, por isso muitas vezes torna-se difícil o acesso dos animais à água, o uso de bombas elétricas resulta em gasto alto de energia e investimento. A implantação do carneiro hidráulico torna-se uma estratégia econômica de grande valia, pois utiliza as diferenças de pressão para bombear a água, sem gasto de energia.

Declarado o difícil acesso à água potável para o consumo dos assentados e para a produção vegetal e animal, fez-se necessário a realização de uma palestra sobre proteção e conservação de minas d'água, na qual foi reforçada a importância de preservar os recursos hídricos naturais para que os mesmos possam ser utilizados e não se tornem escassos.

O assentamento Eli Vive possui uma área extensa, o que dificulta o contato com todos os produtores. Assim, a UDPLP foi uma alternativa encontrada pelos integrantes do projeto, como forma de extensão, visando criar um exemplo vivo de técnicas necessárias para a produção de leite, ajudando na construção e reconstrução do conhecimento, por meio de demonstração, acompanhamento, avaliação e adoção (RAMOS, 2013). Fato importante, visto que o assentamento é recente, com elevado número de famílias assentadas e com muitas famílias sem tradição rural. 
Desenvolvimento de uma unidade demonstrativa de produção agroecológica de leite em assentamento rural

A falta de prática em trabalhar e desenvolver ideias em grupo são barreiras a serem enfrentadas pelo processo de extensão rural (LANDINI, 2015). Por conseguinte, os resultados positivos consequentes das atividades realizadas pelo projeto devem favorecera participação de um maior número de assentados, oportunizando e ampliando a troca de conhecimento e experiências entre os produtores, discentes e docentes envolvidos no projeto.

O projeto contribuiu muito para a formação extensionista dos acadêmicos de graduação. O acompanhamento semanal da produção familiar de leite, vivenciando as limitações tecnológicas e financeiras da atividade, foi de fato bastante interessante, pois proporcionou aos acadêmicos experimentar a metodologia de ensino denominada "Aprendizado Baseado em Problemas (Problem Based Learning - PBL)", tendo os docentes o papel de tutores dos acadêmicos, orientando-os na busca de soluções (BOROCHOVICIUS e TORTELLA, 2014).

Ao final do Projeto, foi organizado um evento intitulado o "CAMPO NO CAMPUS" (Figura 3), com o intuito de proporcionar aos assentados a oportunidade de conhecer a Universidade Estadual de Londrina. Os assentados foram recebidos na UEL pelos discentes e docentes do projeto e pelo Pró-Reitor de Extensão. Após uma breve explanação sobre a UEL, os assentados conheceram os laboratórios onde eram realizadas as análises demandadas no projeto (Laboratório de Inspeção e Análise de Leite, Laboratório de Microbiologia e o Laboratório de Solos), o Orquidário, o Horto Botânico e o Centro de Produção de Leite, onde tiveram uma aula prática sobre ordenha mecânica. A programação contemplou também um café da manhã de recepção, uma caminhada pelo calçadão e almoço no restaurante universitário.

Figura 3 - Visita dos assentados ao Campus da UEL. (a) Horto botânico; (b) sala de ordenha da Fazenda escola.

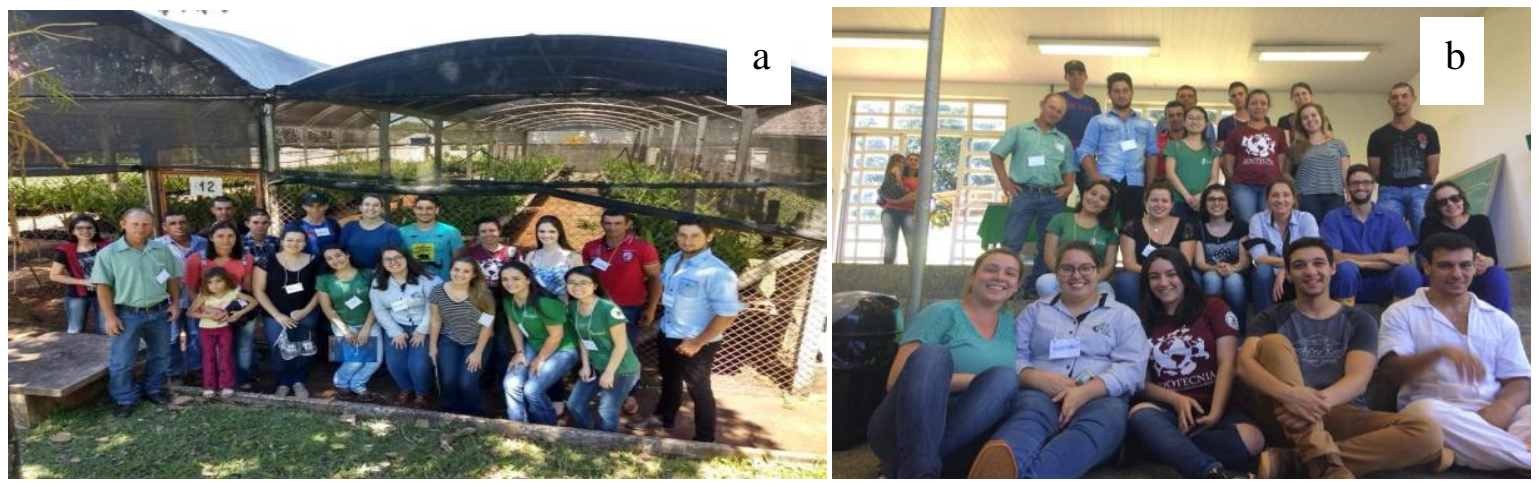

Fonte: Acervo do projeto

\section{CONSIDERAÇÕES FINAIS}


Desenvolvimento de uma unidade demonstrativa de produção agroecológica de leite em assentamento rural

Com as atividades práticas demonstrativas e visitas técnicas realizadas no âmbito do projeto de extensão "Desenvolvimento Participativo da Cadeia Produtiva Sustentável de Leite em Assentamento Rural" foi possível detectar e solucionar problemas, buscar inovações de baixo custo para o sistema de produção, implementar aspectos agroecológicos de produção e capacitar os assentados.

A contextualização dos acadêmicos na realidade de produção sustentável em pequenas propriedades e o entendimento das questões agrárias foram importantes, pois atendem ao Projeto Político Pedagógico dos cursos de graduação na área de Ciências Agrárias, que contemplam o aprendizado com o objetivo de desenvolverem competências e habilidades para atuar, integrar e intervir na realidade social, econômica, política e cultural, promovendo o desenvolvimento, o bem-estar e a qualidade de vida dos cidadãos e comunidades. O projeto de extensão, que agrega docentes, discentes e profissionais recém-formados, favoreceu o desenvolvimento de linhas de pesquisa em produção sustentável, com base nas dificuldades verificadas a campo.

Com o presente trabalho foi possível constatar que a extensão rural é um processo minucioso, desta forma algumas atividades não exibem resultados imediatos e têm como principal objetivo instruir e capacitar os assentados para que os mesmos realizem diariamente em suas propriedades as práticas abordadas e, consequentemente, obtenham os resultados positivos almejados.

\section{AGRADECIMENTOS}

À Universidade Estadual de Londrina, representada pela Pró-Reitoria de Extensão, pelo apoio na condução do projeto e por disponibilizar transporte para a realização das visitas.

À Secretaria da Ciência, Tecnologia e Ensino Superior (SETI) e MEC/SESU/FNDE pela concessão das bolsas e apoio financeiro ao projeto.

\section{REFERÊNCIAS}

ANDRADE, C.M.S. Pastejo rotacionado: Tecnologia para aumentar a produtividade de leite e a longevidade das pastagens. Acre: Embrapa, 2008. Disponível em http://iquiri.cpafac.embrapa.br/prodleite/pdf/pastejo_mauricio.pdf. Acesso em 03 de jul. 2017.

BATTAGLINI, A. P. P. et al. Difusão de boas práticas e caracterização de propriedades leiteiras. Archivos de Zootecnia [s.l], vol. 62, n. 237, p.151-154. 2013. 
BOROCHOVICIUS, E; TORTELLA, J.C.B. Aprendizagem Baseada em Problemas:um método deensino-aprendizageme suas práticas educativas.Ensaio: avaliação de políticas públicasem educação, Rio de Janeiro, v.22, n. 83, p. 263-294, abr./jun. 2014.

COSTABEBER, J. A.; CAPORAL, F. R. "Possibilidades e alternativas do desenvolvimento rural sustentável". In: VELA, Hugo. (Org.): Agricultura Familiar e Desenvolvimento Rural Sustentável no Mercosul. Santa Maria: Editora da UFSM/Pallotti, 2003. p.157-194.

GONÇALVES, A. C. S. et al. Assistência técnica e extensão rural: sua importância para a melhoria da produção leiteira. Relato de caso.Revista Brasileira de Higiene e Sanidade Animal,[s.1.], v. 8, n. 3, p.47-61, set. 2014.

KUMMER, L. Metodologia participativa no meio rural: Uma visão interdisciplinar, conceitos, fundamentos e vivências. Salvador: GTZ. 155p. 2007.

LANDINI, F. P. Problemas enfrentados por extensionistas rurais brasileiros e sua relação com suas concepções de extensão rural. Ciência Rural, [s.l.], v. 45, n. 2, p.371-377, fev. 2015.

RAMOS, G.L.; GOMES, A.P; BARROS, A.A.F. Manual de metodologia de extensão rural. Recife: Instituto Agronômico de Pernambuco, IPA, 2013. 58 p.

ROCHA, F. E. C.; GASTAL, M. L.; TAKATSUKA, F. S.; LOBO, V.J.; SILVA, M. G. Desenvolvimento organizacional rural II: planejamento participativo em associações de agricultores de base familiar. Planaltina: EMBRAPA CERRADO, 50p. 2001.

SOARES, A.B. et al. Produção animal e de forragem em pastagem nativa submetida a distintas ofertas de forragem.Ciência Rural, [s.1.], v. 35, n. 5, p. 1148-1154, 2005.

VAZQUEZ, V. C.; FONSECA, M.I. Importance of partnership university extension and rural extension to the improvement of milk production on family farms.Revista Brasileira de Higiene e Sanidade Animal,[s.l.], v. 8, n. 5, p.131-139, 2014.

Recebido em: 19/10/2019

Aceito em: 13/02/2020 